\title{
A Systemic Review and Experts' Consensus for Long-acting Injectable Antipsychotics in Bipolar Disorder
}

\author{
Yuan Hwa Chou', Po-Chung Chu ${ }^{2,3}$, Szu-Wei Wu, Jen-Chin Lee ${ }^{5}$, Yi-Hsuan Lee ${ }^{6}$, I-Wen Sun ${ }^{7}$, Chen-Lin Chang ${ }^{8}$, \\ Chien-Liang Huang ${ }^{9}, 1-$ Chao Liu $^{10}$, Chia-Fen Tsai ${ }^{11}$, Yung-Chieh Yen ${ }^{12}$ \\ 'Department of Psychiatry, Taipei Veterans General Hospital \& National Yang Ming University, Taipei, ${ }^{2}$ Department of Psychiatry, Chung \\ Shan Medical University Hospital, Taichung, ${ }^{3}$ School of Medicine, Chung Shan Medical University, Taichung, ${ }^{4}$ Department of Psychiatry, \\ Wei-Gong Memorial Hospital, Miaoli, ${ }^{5}$ Department of General Psychiatry, Taoyuan Psychiatric Center, Ministry of Health and Welfare, \\ Taoyuan, ${ }^{6}$ Department of Psychiatry, Tainan Municipal Hospital, Tainan, ${ }^{7}$ Department of Psychiatry, Mackay Memorial Hospital, Taipei, \\ ${ }^{8}$ Department of Psychiatry, Kaohsiung Armed Forces General Hospital, Kaohsiung, ${ }^{9}$ Department of Psychiatry, China Medical University \\ Hospital, Taichung, ${ }^{10}$ Department of Psychiatry, Cardinal Tien Hospital, Taipei, "Department of Psychiatry, Taipei Veterans General Hospital, \\ ${ }^{12}$ Department of Psychiatry, E-Da Hospital, Kaohsiung, Taiwan
}

\begin{abstract}
Bipolar disorder $(\mathrm{BD})$ is a major psychiatric disorder that is easily misdiagnosed. Patient adherence to a treatment regimen is of utmost importance for successful outcomes in BD. Several trials of antipsychotics suggested that depot antipsychotics, including long-acting first- and second-generation agents, are effective in preventing non-adherence, partial adherence, and in reducing relapse in $\mathrm{BD}$. Various long-acting injectable (LAl) antipsychotics are available, including fluphenazine decanoate, haloperidol decanoate, olanzapine pamoate, risperidone microspheres, paliperidone palmitate, and aripiprazole monohydrate. Due to the increasing number of BD patients receiving LAl antipsychotics, treatment guidelines have been developed. However, the clinical applicability of LAl antipsychotics remains a global cause for concern, particularly in Asian countries. Expert physicians from Taiwan participated in a consensus meeting, which was held to review key areas based on both current literature and clinical practice. The purpose of this meeting was to generate a practical and implementable set of recommendations for LAl antipsychotic use to treat BD; target patient groups, dosage, administration, and adverse effects were considered. Experts recommended using LAl antipsychotics in patients with schizophrenia, rapid cycling BD, BD I, and bipolar-type schizoaffective disorder. LAl antipsychotic use was recommended in BD patients with the following characteristics: multiple episodes and low adherence; seldom yet serious episodes; low adherence potential per a physician's clinical judgment; preference for injectable agents over oral agents; and multiple oral agent users still experiencing residual symptoms.
\end{abstract}

KEY WORDS: Bipolar disorder; Long-acting injectable antipsychotics; Risperidone; Consensus.

\section{BACKGROUND}

Bipolar disorder (BD) is a major psychiatric disorder that is easily misdiagnosed. ${ }^{1)}$ It is a life-long illness characterized by recurrent and fluctuating episodes of depression and mania. ${ }^{2)}$ In addition to causing disability and functional impairment, ${ }^{3)} \mathrm{BD}$ also increases all-cause mortality. ${ }^{4)}$ Antipsychotics are efficacious in treating BD in both adults and youths. Although lithium and anticonvulsants are the first-line treatments for $\mathrm{BD}$, there is

\footnotetext{
Received: October 10, 2014 / Revised: December 30, 2014

Accepted: January 19, 2015

Address for correspondence: Yuan Hwa Chou, MD, PhD Department of Psychiatry, Taipei Veterans General Hospital, No 201, Sec 2, Shih Pai Rd, Beitou, Taipei 112, Taiwan Tel: +886-2-2871-1290, Fax: +886-2-2871-1290 E-mail: c520608@ms64,hinet,net
}

growing evidence in favor of atypical antipsychotics as efficacious treatment options. ${ }^{5)}$

\section{MAIN SUBJECTS}

\section{Insight into BD Patient Treatment Adherence}

Patient adherence to a treatment regimen is of utmost importance for successful outcomes in BD. However, up to half of patients with $\mathrm{BD}$ are non-adherent or only partially adherent to antipsychotic treatment. ${ }^{6}$ Non-adherence and partial adherence both also appear to play a significant role in BD relapse. Several antipsychotic trials suggested that depot antipsychotics, including long-acting first- and second-generation agents, are effective in reducing relapse in BD. ${ }^{7}$ In the Clinical Antipsychotic Trials of Intervention Effectiveness (CATIE) study, $74 \%$ of pa- 
tients with schizophrenia discontinued their prescribed drug use within 18 months due to either poor tolerability or lack of efficacy. ${ }^{8}$ However, patients and their families may choose long-acting injectable (LAI) antipsychotics over oral formulations to decrease the frequency and severity of relapse, or for convenience. Gutiérrez-Rojas et $a l^{9)}$ conducted a retrospective and naturalistic study consisting of patients with a Diagnostic and Statistical Manual of Mental Disorders, fourth edition (DSM-IV) BD diagnosis, which suggested that avoiding a delay in diagnosis and enhancing treatment adherence might be important targets for reducing $\mathrm{BD}$ recurrence.

\section{LAI Antipsychotics for BD Treatment}

In the early years of antipsychotic drug therapy, it became clear that depot formulations of antipsychotic drugs, which can maintain therapeutic plasma levels for several weeks, could partially solve the problem of non-adherence. Although patients treated with second-generation antipsychotics showed moderately better therapy adherence than those treated with older drugs, long-acting formulations were also required for second-generation antipsychotics. ${ }^{8)}$ When patients were switched to the LAI form, objective clinical efficacy that exceeded that of oral atypical antipsychotics was observed in clinical studies (as per psychiatric symptom scores and relapse data). Further, patients accepted the LAI dosing, and experienced fewer extrapyramidal side effects. ${ }^{8}$ Table 1 shows various available LAI options.

\section{Fluphenazine decanoate}

Fluphenazine decanoate is a first-generation LAI that has a relatively short duration of action. The initial test dose is $12.5 \mathrm{mg}$. Maintenance doses are in the range of 12.5-100 mg, given every 2-5 weeks. Doses that are substantially less than $25 \mathrm{mg}$ every 2 weeks greatly increase the risk of relapse. ${ }^{10,11)}$

\section{Haloperidol decanoate}

Haloperidol decanoate is a first-generation LAI for which it is possible to administer a loading dose so that no overlapping taper is required. Doses of around $100 \mathrm{mg} \mathrm{ev}-$ ery 4 weeks are likely optimal; relapse prevention is not improved by higher doses. Similar to fluphenazine decanoate, haloperidol decanoate is relatively inexpensive. ${ }^{10,11)}$

\section{Olanzapine pamoate}

Olanzapine pamoate is a second-generation LAI. Clinicians in the United States who administer olanzapine pamoate must enroll in a national registry that documents the incidence of rare but serious adverse drug events, particularly orthostatic hypotension and post-injection delirium/sedation syndrome ( $0.1 \%$ incidence) at every injection. Patients should be observed for 3 hours after every dose, and oral medication overlap may be necessary in some cases. These monitoring difficulties and the expense may limit olanzapine LAI use, even in patients who are likely to benefit. ${ }^{10,11)}$

\section{Risperidone microspheres}

Risperidone microspheres, a second-generation LAI, dosing usually begins at $25 \mathrm{mg}$ or $37.5 \mathrm{mg}$, according to the dose of previously received antipsychotics. Supplementary oral antipsychotic treatment is required for 3 weeks after the first risperidone LAI (Risperdal ${ }^{\mathbb{R}}$ Consta $^{\mathbb{R}}$; Janssen Pharmaceuticals, Inc., Titusville, FL, USA). Dosing is only licensed at 2-week intervals, although there is emerging evidence that monthly dosing might be effective. ${ }^{11)}$ The maximum licensed dose is $50 \mathrm{mg}$ every 2 weeks. ${ }^{10-12)}$

\section{Paliperidone palmitate}

Paliperidone was approved by the United States Food and Drug Administration (FDA) for the treatment of schizoaffective disorder in 2009. For patients naïve to oral paliperidone or injectable risperidone, overlapping oral

Table 1. Characteristics of various long-acting injectable antipsychotics

\begin{tabular}{|c|c|c|c|c|c|c|}
\hline Characteristic & Fluphenazine ${ }^{10,11)}$ & Haloperidol $^{10,11)}$ & Olanzapine $e^{10,11)}$ & Risperidone $e^{10-12)}$ & Paliperidone ${ }^{10,11)}$ & Aripiprazole $e^{13,14)}$ \\
\hline Dose range (mg) & $12.5-100$ & $20-450$ & $150-405$ & $12.5-50$ & $39-234$ & $160-400$ \\
\hline Oral elimination half-life & 1 day & 1 day & 1.5 days & 1 day & 1 day & 3 days \\
\hline Formulation & $\begin{array}{c}\text { Decanoate in } \\
\text { organic oil }\end{array}$ & $\begin{array}{c}\text { Decanoate in } \\
\text { organic oil }\end{array}$ & $\begin{array}{l}\text { Pamoate } \\
\text { crystalline }\end{array}$ & Microspheres & $\begin{array}{l}\text { Palmitate } \\
\text { crystalline }\end{array}$ & $\begin{array}{c}\text { Monohydrate } \\
\text { (lyophilized powder) }\end{array}$ \\
\hline Time between injections & 7 to 21 days & 28 days & 14 to 28 days & 14 days & 28 days & 30 days \\
\hline $\begin{array}{l}\text { Overlap with } \\
\text { oral formulation }\end{array}$ & 1 week & 4 weeks & None & 3 weeks & Need & 2 weeks \\
\hline Loading dose/ initiation & Possible & Possible & Required & None & Required & None \\
\hline
\end{tabular}


taper is necessary. ${ }^{10,11)}$

\section{Aripiprazole monohydrate}

FDA approved aripiprazole monohydrate LAI for the treatment of schizophrenia on February 28, 2013. To maintain therapeutic concentration, concurrent use of oral aripiprazole or other antipsychotic is recommended for 14 days. The available strengths are 300 and $400 \mathrm{mg}$. ${ }^{13,14)}$

First-generation LAI antipsychotics are not approved for use in BD. Among second-generation LAI antipsychotics, only risperidone LAI has been studied and approved for BD maintenance treatment. Although firstgeneration LAI antipsychotics may be effective in reducing manic relapses, they may increase the risk of worsening depression. Further studies are needed in BD patients to determine the usefulness of new LAI antipsychotics, including olanzapine pamoate, paliperidone palmitate and aripiprazole monohydrate. ${ }^{15)}$

Risperidone is a benzisoxazole derivative atypical antipsychotic indicated for the treatment of bipolar mania. The efficacy of risperidone monotherapy for the acute treatment of mania has been demonstrated in several trials, which showed that risperidone monotherapy is superior to placebo and equivalent to haloperidol. ${ }^{16)}$ Evidence supporting the use of risperidone LAI for BD includes: several nonrandomized, open-label studies; one randomized, open-label trial; and two adequately powered randomized, double-blind trials. These studies showed that risperidone LAI was effective in preventing relapse during bipolar maintenance treatment. In double-blind studies, risperidone LAI was associated with reduced relapse rates, increased time to relapse, and greater control of clinical symptoms during maintenance treatment following initial stabilization, compared with oral medication treatment or placebo injection. ${ }^{17,18)}$

Yatham et al. ${ }^{19)}$ were the first to employ a randomized design in a Canadian 6-month prospective open-label pilot trial. Forty-nine patients with BD I or II were treated with a mood stabilizer and an oral second-generation antipsychotic at baseline, and were then randomized to either continue their respective antipsychotic regimens $(n=26)$ or to be switched to risperidone LAI ( $\mathrm{n}=23)$. The switch-

Table 2. Characteristics of clinical trials of risperidone LAI in bipolar disorder

\begin{tabular}{|c|c|c|c|c|}
\hline $\begin{array}{l}\text { Study and } \\
\text { bipolar subtype (BP) }\end{array}$ & Methodology & Duration & $\begin{array}{l}\text { Dose* } \\
\text { (mg) }\end{array}$ & Outcome \\
\hline $\begin{array}{l}\text { Savas et } a l^{20)} \\
(2006) \\
\text { BP I }(n=12)\end{array}$ & $\begin{array}{l}\text { Open-label/chart review/acute/ } \\
\text { no monotherapy }\end{array}$ & 24 weeks & $25-50$ & $\begin{array}{l}\text { 100\% response; } 92 \% \text { remission; } \\
\text { acute significant decrease in BRMAS; } \\
\text { no significant change in HAMD }\end{array}$ \\
\hline $\begin{array}{l}\text { Han et } a l^{21)} \\
(2007) \\
\text { BP । }(n=10)\end{array}$ & $\begin{array}{l}\text { Open-label/observational/ } \\
\text { relapse prevention/no monotherapy }\end{array}$ & 52 weeks & $25-37.5$ & $\begin{array}{l}\text { No significant change in YMRS; } \\
\text { no significant change in HAMD }\end{array}$ \\
\hline $\begin{array}{l}\text { Yatham et al. }{ }^{19)} \\
(2007) \\
\text { BP । }(n=32) \\
\text { BP ॥ }(n=17)\end{array}$ & $\begin{array}{l}\text { Open-label/randomized/ } \\
\text { relapse prevention/no monotherapy }\end{array}$ & 24 weeks & $25-50$ & $\begin{array}{l}\text { Significant reduction in YMRS scores (no difference } \\
\text { from OAA group); no change in MADRS scores } \\
\text { (no difference from OAA) }\end{array}$ \\
\hline $\begin{array}{l}\text { Malempati et } a l^{22)} \\
(2008) \\
\text { BP । }(n=8) \\
\text { BP ॥ }(n=2)\end{array}$ & $\begin{array}{l}\text { Open-label/observational/ } \\
\text { relapse prevention/no monotherapy }\end{array}$ & 104 weeks & $25-50$ & $50 \%$ relapse \\
\hline $\begin{array}{l}\text { Macfadden et } a . .^{17)} \\
(2009) \\
\text { BP । }(n=124)\end{array}$ & $\begin{array}{l}\text { Randomized/double-blind/ } \\
\text { placebo-controlled/relapse prevention/ } \\
\text { no monotherapy }\end{array}$ & 52 weeks & $25-50$ & $\begin{array}{l}\text { Delay in relapse; no significant reduction in } \\
\text { YMRS and MADRS scores }\end{array}$ \\
\hline $\begin{array}{l}\text { Quiroz et } a l^{23)} \\
(2010) \\
\text { BP । }(n=303)\end{array}$ & $\begin{array}{l}\text { Randomized/controlled/ } \\
\text { relapse prevention/monotherapy }\end{array}$ & 24 months & 25 & $\begin{array}{l}\text { Significantly delay in time to recurrence of } \\
\text { mood episodes }\end{array}$ \\
\hline $\begin{array}{l}\text { Macfadden et } a .^{24)} \\
(2011) \\
\text { BP । }(n=144) \\
\text { BP } \|(n=18)\end{array}$ & $\begin{array}{l}\text { Exploratory analysis/open-label/ } \\
\text { relapse prevention (patients with active } \\
\text { mood symptoms)/no monotherapy }\end{array}$ & 16 weeks & $25-50$ & $\begin{array}{l}\text { Significant improvements were observed for } \\
\text { the total population on the CGI-BP-S, MADRS, } \\
\text { and YMRS scales }\end{array}$ \\
\hline $\begin{array}{l}\text { Vieta et } a l^{18)} \\
(2012) \\
\operatorname{BP} \mid(n=398)\end{array}$ & $\begin{array}{l}\text { Randomized, double-blind, } \\
\text { placebo-controlled trial/ } \\
\text { relapse prevention/monotherapy }\end{array}$ & 18 months & $25-50$ & $\begin{array}{l}\text { Delay in time to recurrence of elevated } \\
\text { mood episodes }\end{array}$ \\
\hline
\end{tabular}

*Per 2 weeks.

BRMAS, Bech-Rafaelson Mania Rating Scale; HAMD, Hamilton Depression Rating Scale; LAR, long-acting risperidone; MADRS, Montgomery-Asberg Depression Rating Scale; OAA, oral atypical antipsychotic; YMRS, Young Mania Rating Scale; CGI-BP-S, Clinical Global Impressions of Bipolar Disorder-Severity. 
over to risperidone LAI did not cause significant changes in efficacy or safety parameters, indicating its therapeutic equivalence to oral antipsychotic add-on therapies. ${ }^{8,19)}$ Similar results were found in various subsequent trials, which are summarized in Table 2., ${ }^{2,-24)}$

Two randomized controlled trials investigated the efficacy of risperidone LAI monotherapy for the prevention of treatment-emergent episodes in patients that experienced a manic/mixed index episode after successful stabilization on oral risperidone and who were then switched to risperidone LAI. Over 2 years, Quiroz et $a l^{23)}$ compared risperidone LAI monotherapy against placebo injections in 303 patients who were stabilized for 6 months on risperidone LAI after a manic/mixed index episode. Most of the patients in the risperidone LAI group (77\%) remained on the minimum dose of $25 \mathrm{mg}$ every 2 weeks. In the risperidone LAI group, 42 of 140 patients (30\%) experienced recurrence during double-blind treatment versus 76 of 135 $(56 \%)$ in the placebo group. Patients in the risperidone LAI group were less than half as likely to experience a recurrence as patients in the placebo group. Time to recurrence for elevated mood episodes was significantly longer in the risperidone LAI group than in the placebo group, but time to recurrence for depressive episodes did not differ. ${ }^{23)}$ The second study was conducted in an enriched population by Vieta et al. ${ }^{18)}$ and included an olanzapine arm in addition to risperidone LAI and placebo arms to increase the assay sensitivity. Time to recurrence of an elevated (hypomanic, manic, or mixed) mood episode was significantly longer with risperidone LAI compared with placebo. There was no significant difference in time to recurrence of a depressive episode between risperidone LAI and placebo. However, olanzapine was significantly superior to both risperidone LAI and placebo in all primary outcome variables. ${ }^{18)}$

\section{Advantages and Limitations of LAl Antipsychotics}

First-generation LAI medications are advantageous because medication delivery ensures the administration of the prescribed dose. Efficacy benefits are mostly due to the fact that the injectable form increases treatment adherence. However, there are important limitations to the long-term use of first-generation typical antipsychotics in patients with $\mathrm{BD}$, including risk of extrapyramidal side effects and tardive dyskinesia, which may exceed that of patients with schizophrenia, and the potential for treatment-emergent exacerbation of depressive symptoms. ${ }^{8,25)}$ Other disadvantages specific to LAI antipsychotics are complications at the injection site, such as nodules and in- durations, muscle granulomas, fibrosis, abscess formation, and oil accumulation after repeated injections. These problems, which are observed in up to a quarter of patients, are associated with concentrated preparations, higher doses, larger volumes, weekly injections, and prolonged treatment. ${ }^{26)}$

Risperidone LAI, the only second-generation LAI antipsychotic approved for BD treatment, shows good tolerability across all studies. However, dose-related extrapyramidal effects, sedation, weight gain, and prolactin elevation may occur during long-term treatment. ${ }^{15)}$

\section{Acute Treatment vs. Relapse Prevention in BD}

The goal of acute treatment in BD is to stabilize the patient's mood, whereas the goal of maintenance treatment is to prevent relapse. ${ }^{27)}$ Some frequently used FDA-approved agents for acute mania include aripiprazole, carbamazepine, divalproex, lithium, olanzapine, paliperidone, quetiapine, and risperidone. Agents used for bipolar depression include lamotrigine, lithium, modafinil, olanzapine plus fluoxetine, pramipexole, and quetiapine. FDAapproved agents for BD maintenance treatment include: aripiprazole, lamotrigine, olanzapine, and Risperidone ${ }^{\mathbb{R}}$ Consta ${ }^{\mathbb{R}}$ as monotherapies; asenapine, oxcarbazepine, quetiapine, and ziprasidone as add-on agents to lithium or valproate. ${ }^{28)}$ Patients with poor adherence or those who will not accept long-term oral treatment are given a LAI formulation as the first-line treatment. BD patients for whom second-generation LAIs are an effective treatment are candidates for second-generation LAIs, either as monotherapy or combination therapy. First-generation LAIs are not recommended for maintenance treatment. When switching from an oral antipsychotic (first or second generation) to an LAI form, it is recommended to start with the oral antipsychotic for the length of time required to obtain an effective dose and good tolerance before switching to the LAI form. ${ }^{29)}$

\section{Treatment Guidelines}

Various guidelines recommend the use of LAI antipsychotics for the treatment of BD. Some of these important international guidelines are summarized in Table 3.

\section{Canadian Network for Mood and Anxiety Treatments (CANMAT) guidelines}

As per CANMAT guidelines for the management of patients with BD, 2013 update: "lithium, lamotrigine, valproate, olanzapine, quetiapine, aripiprazole, long-acting risperidone injection, and adjunctive ziprasidone continue 
Table 3. Maintenance pharmacotherapy as per various guidelines

\begin{tabular}{|c|c|c|}
\hline Guidelines & Reference & Maintenance treatment \\
\hline $\begin{array}{l}\text { CANMAT (Canadian Network for } \\
\text { Mood and Anxiety Treatments) }\end{array}$ & Yatham et $a l^{30)}$ (2013) & $\begin{array}{l}\text { Lithium, lamotrigine, valproate, olanzapine, quetiapine, } \\
\text { aripiprazole, risperidone long-acting injection, } \\
\text { and adjunctive ziprasidone }\end{array}$ \\
\hline $\begin{array}{l}\text { APA } \\
\text { (American Psychiatric Association) }\end{array}$ & $\begin{array}{l}\text { American Psychiatric } \\
\text { Association }^{16)}(2002)\end{array}$ & $\begin{array}{l}\text { Lithium, valproate, lamotrigine, carbamazepine, } \\
\text { oxcarbazepine }\end{array}$ \\
\hline $\begin{array}{l}\text { BAP (British Association for } \\
\text { Psychopharmacology) }\end{array}$ & $\begin{array}{l}\text { Goodwin and Consensus Group of } \\
\text { the British Association for Psyco- } \\
\text { pharmacology }{ }^{31)} \text { (2009) }\end{array}$ & $\begin{array}{l}\text { Mania predominates: lithium, aripiprazole, quetiapine, } \\
\text { valproate or olanzapine, risperidone LAI (manic relapse) } \\
\text { Depression predominates: quetiapine, lamotrigine }\end{array}$ \\
\hline $\begin{array}{l}\text { WFSBP (World Federation of } \\
\text { Societies of Biological Psychiatry) }\end{array}$ & $\begin{array}{l}\text { Grunze et al. } \\
(2009,2010,2013)\end{array}$ & $\begin{array}{l}\text { Lithium, carbamazepime, valproate, risperidone LAI, } \\
\text { olanzapine, aripiprazole, ziprasidone }\end{array}$ \\
\hline $\begin{array}{l}\text { NICE (National Institute for Health and } \\
\text { Clinical Excellence) Guidance }\end{array}$ & $\begin{array}{l}\text { National Collaborating Centre for } \\
\text { Mental Health }(U K)^{35)}(2006)\end{array}$ & $\begin{array}{l}\text { Lithium, valproate, olanzapine } \\
\text { Recent mania: lithium or valproate } \\
\text { No recent mania: } \\
\text { lamotrigine or quetiapine, lamotriginetantimanic agents, } \\
\text { adjunctive antidepressants (if depressive symptoms) } \\
\text { Rapid cycling: } \\
\text { lithium+valproate }\end{array}$ \\
\hline Texas Medication Algorithm Project & Crismon et $a l^{36)}$ (2007) & $\begin{array}{l}\text { Most recent episode hypomanic/manic/mixed: } \\
\text { lithium, valproate, lamotrigine, olanzapine } \\
\text { Most recent episode depressed: } \\
\text { lamotrigine, antimanic agents }\end{array}$ \\
\hline $\begin{array}{l}\text { Taiwan consensus of pharmacological } \\
\text { treatment for bipolar disorder }\end{array}$ & Bai et $a l^{37)}$ (2013) & $\begin{array}{l}\text { RG-T 1: } \\
\text { Monotherapy: } \\
\text { lithium, lamotrigine and valproic acid and } \\
\text { carbamazepine } \\
\text { Combination/augmentation or adjunctive/add-on therapy: } \\
\text { lithium or valproic acid+quetiapine, } \\
\text { lithium+divalproex and lithium+carbamazepine } \\
\text { RG-T for risperidone LAl, as monotherapy or } \\
\text { combination therapy, is } 2\end{array}$ \\
\hline
\end{tabular}

LAI, long-acting injectable; RG-T, Taiwan recommendation grade.

to be first-line options for maintenance treatment of bipolar disorder", 30)

\section{American Psychiatric Association (APA) guidelines}

Lithium and valproate have the best supportive evidence for maintenance treatment use, with possible alternatives being lamotrigine, carbamazepine, or oxcarbazepine. When patients are already being treated with a maintenance medication or fail to respond to initial treatment, the APA guidelines advise optimization of the maintenance medication, followed by addition of an antidepressant (i.e., lamotrigine, paroxetine, or bupropion). As these guidelines were originally published in 2002 and have yet to be updated, there is no mention of LAI antipsychotics as effective agents for BD treatment. ${ }^{16)}$

\section{British Association for Psychopharmacology (BAP) guidelines}

For long-term treatment, lithium monotherapy should be considered, which is effective against both manic and depressive relapse, although it is more effective in pre- venting mania. If lithium is ineffective or poorly tolerated, other options to consider include aripiprazole, carbamazepine, oxcarbazepine, lamotrigine, olanzapine, quetiapine, or valproate, based upon the patient's clinical condition. Antipsychotics are prescribed for some patients in LAI formulations, as monotherapy or in combination with other agents. Risperidone LAI may be useful in poorly compliant bipolar patients at high risk of manic relapse. ${ }^{31)}$

\section{World Federation of Societies of Biological Psychiatry (WFSBP) guidelines}

As per the 2012 update of WFSBP guidelines for the long-term biological treatment of BD: "different scenarios have to be examined separately: prevention of mania, depression, or an episode of any polarity, both in acute responders and in patients treated de novo. Treatment might differ in Bipolar II patients or Rapid cyclers, as well as in special subpopulations." Several medications have been identified as preventive against new manic episodes, whereas the current state of research into the prevention of new depressive episodes is less satisfactory. Lithium con- 
tinues to be the substance with the broadest base of evidence across all available treatments. ${ }^{32-34)}$

\section{National Institute for Clinical Health and Excellence (NICE) guidelines}

According to NICE guidelines, long-acting intramuscular injections of antipsychotics ('depots,' LAIs) are not recommended for routine use in BD. They may be considered for people who were treated successfully for mania with oral antipsychotics, but have had a relapse because of poor adherence. $^{35)}$

\section{Texas Medication Algorithm Project (TMAP)}

These guidelines do not clearly mention the use of depot formulations in the treatment of bipolar disease. ${ }^{36)}$

\section{The Taiwan consensus of pharmacological treatment for BD}

The Taiwanese Society of Biological Psychiatry and Neuropsychopharmacology (TSBPN) initiated the Taiwan consensus of pharmacological treatment for BD. The purposes of the consensus were to enhance international collaboration, research, and education. During the maintenance phase, Taiwan recommendation grade (RG-T) 1 includes: lithium, lamotrigine, valproic acid, and carbamazepine as monotherapy options; and lithium or valproic acid plus quetiapine, lithium plus divalproex, and lithium plus carbamazepine as combination/augmentation or adjunctive/add-on therapy. RG-T 2 includes risperidone LAI as a monotherapy or combination therapy due to the weight gain side-effect and because it is less efficacious in preventing depressive episodes. ${ }^{37)}$

\section{Expert Opinions from Taiwan}

A consensus meeting, involving expert physicians from Taiwan, reviewed key areas based on literature and clinical practice. With an increasing number of BD patients receiving LAI antipsychotics, several treatment guidelines were developed. However, clinical applicability of LAI antipsychotics remains a global cause for concern, particularly in Asian countries. Therefore, the purpose of this meeting was to compile literature and clinical experiences from Taiwan and to put together a practical and implementable set of recommendations on how to use LAI antipsychotics in the treatment of BD. The recommendations cover LAI antipsychotic use, including target patient group, dosage, administration, and adverse effects.

The experts recommend using LAI antipsychotics in patients with schizophrenia, rapid cycling BD, BD I, and bipolar-type schizoaffective disorder. LAI antipsychotics are equally important for inpatients and outpatients. However, greater adherence and convenient usage makes them more important for outpatients with BD. LAI antipsychotic use is recommended in patients with: (1) multiple episodes and low adherence; (2) seldom but serious episodes; (3) low adherence potential as per a physician's clinical judgment; (4) a preference for injectable agents instead of oral agents; and (5) multiple oral agent usage and remaining residual symptoms.

The experts are of the opinion that LAI antipsychotics can be used both as a monotherapy and as an adjunctive therapy. Risperidone LAI is indicated as a monotherapy or as an adjunctive therapy to lithium or valproate for the maintenance treatment of BD I. Evidence supporting the use of LAI risperidone consists of several clinical trials that demonstrated its efficacy in relapse prevention. In a multicenter, double-blind, placebo-controlled study to show the effectiveness of risperidone LAI as a monotherapy, the inclusion criteria were adult patients who met DSM-IV criteria for BD I, and who were stable on medication or experiencing an acute manic or mixed episode. Time to relapse was delayed in patients receiving risperidone LAI monotherapy as compared to placebo. ${ }^{12)}$ Another multi-center, randomized, double-blind, placebo-controlled trial was conducted to show the effectiveness of LAI risperidone as an adjunctive treatment. The inclusion criteria were adult patients who met DSM-IV criteria for BD I and who experienced at least four mood disorder episodes that required psychiatric/clinical intervention in the previous 12 months, including at least two episodes in the 6 months prior to the start of the study. Time to relapse was delayed in patients receiving adjunctive therapy with risperidone LAI as compared to placebo. ${ }^{12)}$ The expert group was of the opinion that the inclusion criteria in these clinical trials may not always be applicable in clinical practice. In clinical practice, LAI antipsychotics can be used for patients with recurrent episodes and in patients experiencing the acute phase and who are unwilling to use oral agents.

The attending experts agreed that dosage and administration of LAI antipsychotics should follow the results of clinical trials and prescription information. Based on clinical judgment, some patients may need a lower initial dose or longer injection interval. According to the expert's clinical experiences, a steady clinical state can still be maintained even after dose and/or interval modification. If a patient is more prone to extrapyramidal symptoms (EPS) based on his/her medical history, initiating treatment with 
lower dose LAI antipsychotics is appropriate. The expert group was of the opinion that the injection interval for home care patients should follow the prescription information (i.e., 2-week interval for risperidone LAI). On the contrary, for outpatients, a longer duration injection interval may be used (e.g., 3-4 weeks for risperidone LAI) with a higher dose. This modification is based on the experts' clinical experience; its validity is unknown at present. However, although dosing is licensed only at 2-week intervals, emerging literature evidence suggests that monthly dosing might be effective. ${ }^{11)}$ The experts also stressed the need for combining oral risperidone in inpatients while switching to risperidone LAI during the first 3 weeks. There is no need to combine oral risperidone in outpatients who are receiving steady maintenance treatment.

In a recent open-label, 28-week, randomized, controlled trial conducted on stable patients with schizophrenia treated with risperidone or olanzapine oral formulation, the oral risperidone dose was reduced by $50 \%$ at 4 weeks and then maintained. The results of this 6-month pilot study suggested that a $50 \%$ dose reduction could improve cognitive function in stable schizophrenic patients. However, there is a need to confirm the finding through larger scale trials with longer follow-up periods in schizophrenia, and the relevance of the findings in $\mathrm{BD} .{ }^{38)}$ To manage common adverse reactions (e.g., EPSs) that arise during the post-switch period, experts indicate that risperidone LAI adverse events are generally the same as those with oral risperidone. Some experts point out that clinicians should proceed with caution in using risperidone $\mathrm{LAI}$ in $\mathrm{BD}$ patients, as $\mathrm{BD}$ patients are more prone to have EPS as compared to schizophrenic patients. If a depression episode occurs during risperidone LAI treatment, the experts recommend following the bipolar depression treatment guidelines. Reducing the dosage of risperidone LAI is not required.

The attending experts also discussed the fact that risperidone LAI has not been studied in children younger than 18 years, and that the long-term effects of risperidone on growth and sexual maturation should be evaluated further in children and adolescents. Doses should be similar for otherwise healthy elderly patients as for nonelderly patients. Elderly patients should receive special instructions on nonpharmacological interventions that help to reduce the occurrence of orthostatic hypotension. ${ }^{12)}$

\section{CONCLUSIONS AND FUTURE PROSPECTS}

First-generation LAI antipsychotics cause high rates of extrapyramidal side effects and tardive dyskinesia, among other adverse effects, and potentially induce depression. Risperidone LAI, the only second-generation LAI antipsychotic recommended for BD treatment, has important advantages over first-generation drugs with respect to movement disorders. However, its use is complicated and its clinical utility is compromised by excessively delayed release. Further studies with the new LAI antipsychotics (e.g., olanzapine pamoate, paliperidone palmitate, and aripiprazole monohydrate) are needed in $\mathrm{BD}$ patients.

\section{REFERENCES}

1. El-Hage W, Surguladze SA. Emerging treatments in the management of bipolar disorder - focus on risperidone long acting injection. Neuropsychiatr Dis Treat 2010;6:455-464.

2. Kemp DE, Canan F, Goldstein BI, McIntyre RS. Longacting risperidone: a review of its role in the treatment of bipolar disorder. Adv Ther 2009;26:588-599.

3. Simon GE, Bauer MS, Ludman EJ, Operskalski BH, Unützer J. Mood symptoms, functional impairment, and disability in people with bipolar disorder: specific effects of mania and depression. J Clin Psychiatry 2007;68:1237-1245.

4. Osby U, Brandt L, Correia N, Ekbom A, Sparén P. Excess mortality in bipolar and unipolar disorder in Sweden. Arch Gen Psychiatry 2001;58:844-850.

5. Yatham LN, Kennedy SH, O'Donovan C, Parikh SV, MacQueen G, McIntyre RS, et al; Guidelines Group, CANMAT. Canadian Network for Mood and Anxiety Treatments (CANMAT) guidelines for the management of patients with bipolar disorder: update 2007. Bipolar Disord 2006;8:721-739.

6. Sajatovic M, Valenstein M, Blow FC, Ganoczy D, Ignacio $\mathrm{RV}$. Treatment adherence with antipsychotic medications in bipolar disorder. Bipolar Disord 2006;8:232-241.

7. El-Mallakh RS. Medication adherence and the use of long-acting antipsychotics in bipolar disorder. J Psychiatr Pract 2007; 13:79-85.

8. Rainer MK. Risperidone long-acting injection: a review of its long term safety and efficacy. Neuropsychiatr Dis Treat 2008;4:919-927.

9. Gutiérrez-Rojas L, Jurado D, Martínez-Ortega JM, Gurpegui M. Poor adherence to treatment associated with a high recurrence in a bipolar disorder outpatient sample. J Affect Disord 2010;127:77-83.

10. Kennedy WK. When and how to use long-acting injectable antipsychotics. Current Psychiatry 2012;11:40-43.

11. Taylor D. Psychopharmacology and adverse effects of antipsychotic long-acting injections: a review. Br J Psychiatry Suppl 2009;52:S13-S19.

12. Janssen Pharmaceuticals. Risperdal Consta [package insert]. Titusville, NJ:Division of Ortho-McNeil-Janssen Pharmaceuticals Inc.;2011.

13. Gopalakrishna G, Aggarwal A, Lauriello J. Long-acting injectable aripiprazole: how might it fit in our tool box? Clin Schizophr Relat Psychoses 2013;7:87-92.

14. Otsuka Pharmaceutical Company. Abilify Maintena [package insert]. Tokyo, Japan:Otsuka Pharmaceutical Company;2013.

15. Gigante $\mathrm{AD}$, Lafer B, Yatham LN. Long-acting injectable antipsychotics for the maintenance treatment of bipolar disorder. CNS Drugs 2012;26:403-420. 
16. American Psychiatric Association. Practice guideline for the treatment of patients with bipolar disorder (revision). Am J Psychiatry 2002;159:1-50.

17. Macfadden W, Alphs L, Haskins JT, Turner N, Turkoz I, Bossie C, et al. A randomized, double-blind, placebocontrolled study of maintenance treatment with adjunctive risperidone long-acting therapy in patients with bipolar I disorder who relapse frequently. Bipolar Disord 2009;11: 827-839.

18. Vieta E, Montgomery S, Sulaiman AH, Cordoba R, Huberlant B, Martinez L, et al. A randomized, double-blind, placebo-controlled trial to assess prevention of mood episodes with risperidone long-acting injectable in patients with bipolar I disorder. Eur Neuropsychopharmacol 2012;22:825-835.

19. Yatham LN, Fallu A, Binder CE. A 6-month randomized open-label comparison of continuation of oral atypical antipsychotic therapy or switch to long acting injectable risperidone in patients with bipolar disorder. Acta Psychiatr Scand Suppl 2007;(434):50-56.

20. Savas HA, Yumru M, Ozen ME. Use of long-acting risperidone in the treatment of bipolar patients. J Clin Psychopharmacol 2006;26:530-531.

21. Han C, Lee MS, Pae CU, Ko YH, Patkar AA, Jung IK. Usefulness of long-acting injectable risperidone during 12-month maintenance therapy of bipolar disorder. Prog Neuropsychopharmacol Biol Psychiatry 2007;31:1219-1223.

22. Malempati RN, Bond DJ, Yatham LN. Depot risperidone in the outpatient management of bipolar disorder: a 2-year study of 10 patients. Int Clin Psychopharmacol 2008;23: 88-94.

23. Quiroz JA, Yatham LN, Palumbo JM, Karcher K, Kushner $\mathrm{S}$, Kusumakar V. Risperidone long-acting injectable monotherapy in the maintenance treatment of bipolar I disorder. Biol Psychiatry 2010;68:156-162.

24. Macfadden W, Adler CM, Turkoz I, Haskins JT, Turner N, Alphs L. Adjunctive long-acting risperidone in patients with bipolar disorder who relapse frequently and have active mood symptoms. BMC Psychiatry 2011;11:171.

25. Bobo WV, Shelton RC. Risperidone long-acting injectable (Risperdal Consta ${ }^{\mathbb{R}}$ ) for maintenance treatment in patients with bipolar disorder. Expert Rev Neurother 2010;10:16371658.

26. Gray R, Spilling R, Burgess D, Newey T. Antipsychotic long-acting injections in clinical practice: medication management and patient choice. Br J Psychiatry Suppl 2009;52:S51-S56

27. Geddes JR, Miklowitz DJ. Treatment of bipolar disorder. Lancet 2013;381:1672-1682.

28. El-Mallakh RS, Elmaadawi AZ, Gao Y, Lohano K, Roberts RJ. Current and emerging therapies for the management of bipolar disorders. J Cent Nerv Syst Dis 2011;3:189-197.

29. Llorca PM, Abbar M, Courtet P, Guillaume S, Lancrenon $\mathrm{S}$, Samalin L. Guidelines for the use and management of long-acting injectable antipsychotics in serious mental illness. BMC Psychiatry 2013;13:340.

30. Yatham LN, Kennedy SH, Parikh SV, Schaffer A, Beaulieu S, Alda M, et al. Canadian Network for Mood and Anxiety Treatments (CANMAT) and International Society for Bipolar Disorders (ISBD) collaborative update of CANMAT guidelines for the management of patients with bipolar disorder: update 2013. Bipolar Disord 2013;15:1-44.

31. Goodwin GM; Consensus Group of the British Association for Psychopharmacology. Evidence-based guidelines for treating bipolar disorder: revised second edition--recommendations from the British Association for Psychopharmacology. J Psychopharmacol 2009;23:346-388.

32. Grunze H, Vieta E, Goodwin GM, Bowden C, Licht RW, Möller HJ, et al; WFSBP Task Force on Treatment Guidelines for Bipolar Disorders. The World Federation of Societies of Biological Psychiatry (WFSBP) guidelines for the biological treatment of bipolar disorders: update 2012 on the long-term treatment of bipolar disorder. World J Biol Psychiatry 2013;14:154-219.

33. Grunze H, Vieta E, Goodwin GM, Bowden C, Licht RW, Moller HJ, et al. The World Federation of Societies of Biological Psychiatry (WFSBP) guidelines for the biological treatment of bipolar disorders: update 2009 on the treatment of acute mania. World J Biol Psychiatry 2009;10:85-116.

34. Grunze H, Vieta E, Goodwin GM, Bowden C, Licht RW, Möller HJ, et al; WFSBP Task Force On Treatment Guidelines For Bipolar Disorders. The World Federation of Societies of Biological Psychiatry (WFSBP) guidelines for the biological treatment of bipolar disorders: update 2010 on the treatment of acute bipolar depression. World J Biol Psychiatry 2010;11:81-109.

35. National Collaborating Centre for Mental Health (UK). Bipolar disorder: the management of bipolar disorder in adults, children and adolescents, in primary and secondary care. Leicester, UK:British Psychological Society;2006.

36. Crismon ML, Argo TR, Bendele SD, Suppes T. Texas medication algorithm project procedural manual: bipolar disorder algorithms. Austin:Texas Department of State Health Services,2007.

37. Bai YM, Chang CJ, Tsai SY, Chen YC, Hsiao MC, Li CT, et al. Taiwan consensus of pharmacological treatment for bipolar disorder. J Chin Med Assoc 2013;76:547-556.

38. Takeuchi H, Suzuki T, Remington G, Bies RR, Abe T, Graff-Guerrero A, et al. Effects of risperidone and olanzapine dose reduction on cognitive function in stable patients with schizophrenia: an open-label, randomized, controlled, pilot study. Schizophr Bull 2013;39:993-998. 